\title{
Barrio Dreams
}




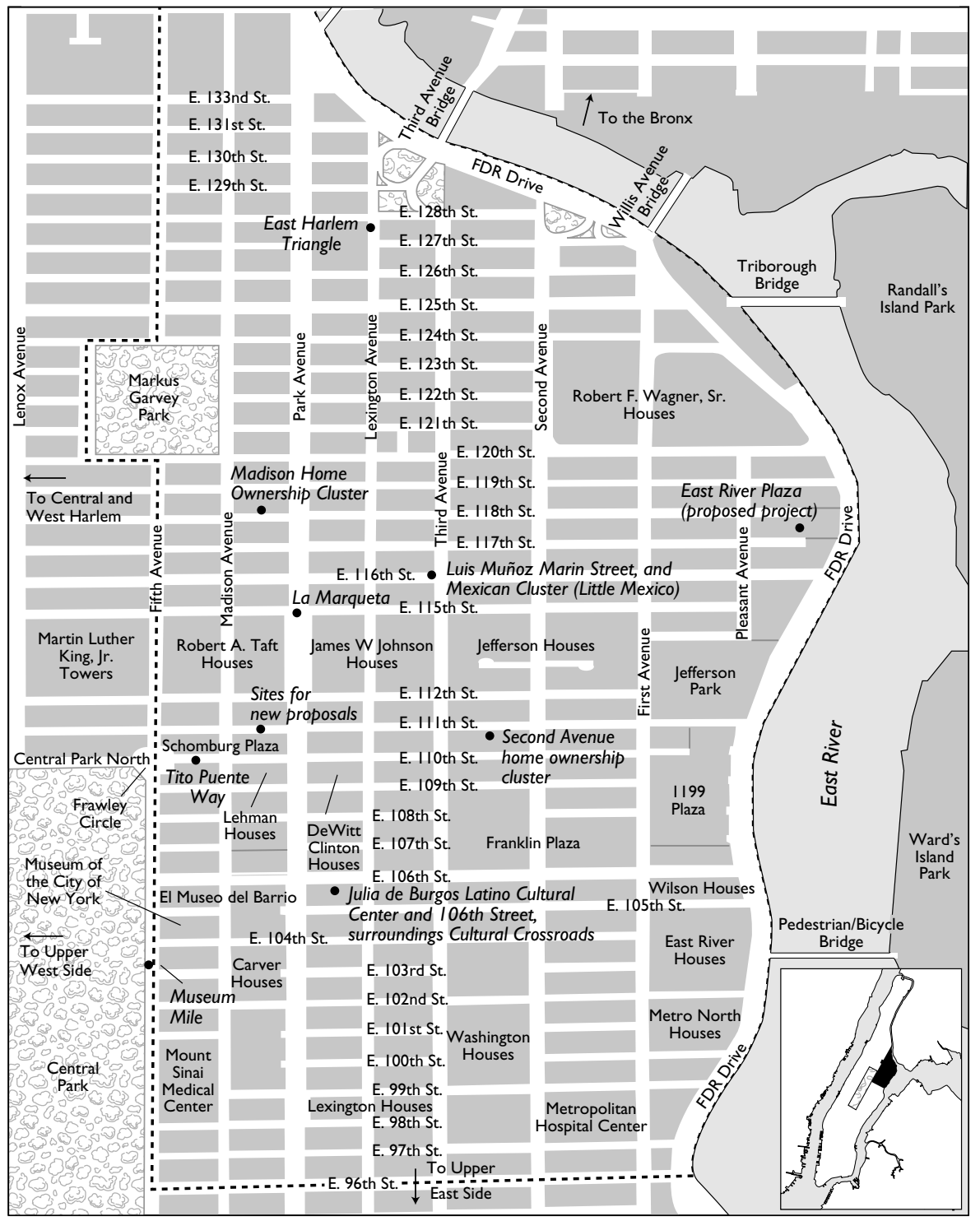

Map of East Harlem. Insert shows its location in Upper Manhattan. 


\section{Barrio Dreams}

P U ERT O R I A A S, LA T I N O S,

A N D T H E N E O L I B ER A L C I T Y

A R L E N E D ÁV I L A

UNIVERSITY OF CALIFORNIA PRESS

Berkeley Los Angeles London 
University of California Press

Berkeley and Los Angeles, California

University of California Press, Ltd.

London, England

(C) 2004 by the Regents of the University of California

Library of Congress Control Number:

2003064572

Manufactured in the United States of America

$\begin{array}{llllllllll}13 & 12 & 11 & 10 & 09 & 08 & 07 & 06 & 05 & 04\end{array}$

$\begin{array}{llllllllll}10 & 9 & 8 & 7 & 6 & 5 & 4 & 3 & 2 & 1\end{array}$

The paper used in this publication meets the minimum requirements of ANSI/NISO Z39.48-1992 (R 1997) (Permanence of Paper). 